\title{
BISON and MARMOT Development for Modeling Fast Reactor Fuel Performance
}

Fuel Cycle Research \& Development Advanced Fuels Campaign

Kyle Gamble, Richard Williamson, Daniel Schwen, Yongfeng Zhang, Stephen Novascone, Pavel Medvedev

Prepared for U.S. Department of Energy Office of Nuclear Energy

September 2015 FCRD-FUEL-2015-XXXXXX 


\section{DISCLAIMER}

This information was prepared as an account of work sponsored by an agency of the U.S. Government. Neither the U.S. Government nor any agency thereof, nor any of their employees, makes any warranty, expressed or implied, or assumes any legal liability or responsibility for the accuracy, completeness, or usefulness, of any information, apparatus, product, or process disclosed, or represents that its use would not infringe privately owned rights. References herein to any specific commercial product, process, or service by trade name, trade mark, manufacturer, or otherwise, does not necessarily constitute or imply its endorsement, recommendation, or favoring by the U.S. Government or any agency thereof. The views and opinions of authors expressed herein do not necessarily state or reflect those of the U.S. Government or any agency thereof. 
INL/EXT-15-36440

Revision 0

\title{
BISON and MARMOT Development for Modeling Fast Reactor Fuel Performance
}

\author{
Kyle Gamble, Richard Williamson, Daniel Schwen, Yongfeng Zhang, Stephen \\ Novascone, Pavel Medvedev
}

September 2015

Idaho National Laboratory Idaho Falls, Idaho 83415

http://www.inl.gov

Prepared for the

U.S. Department of Energy

Office of Nuclear Energy

Under DOE Idaho Operations Office

Contract DE-AC07-05ID14517 
INTENTIONALLY BLANK 


\begin{abstract}
BISON and MARMOT are two codes under development at the Idaho National Laboratory for engineering scale and lower length scale fuel performance modeling. So far, the majority of development has been focused on fuels of light water reactors. It is desired to add capabilities for fast reactor applications to these codes. The fast reactor fuel types under consideration are metal (U-Pu-Zr) and oxide (MOX). The cladding types of interest include 316SS, D9, and HT9. The purpose of this report is to outline the proposed plans for code development and provide an overview of the models added to the BISON and MARMOT codes for fast reactor fuel behavior through the end of FY-2015. A brief overview of preliminary discussions on the formation of a bilateral agreement between the Idaho National Laboratory and the National Nuclear Laboratory in the United Kingdom is presented.
\end{abstract}


INTENTIONALLY BLANK 


\section{CONTENTS}

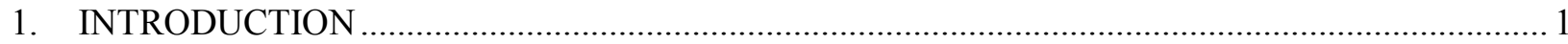

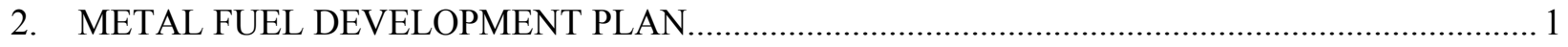

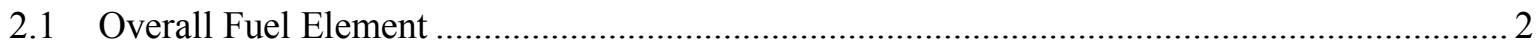

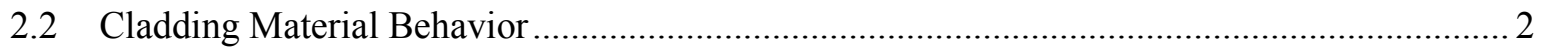

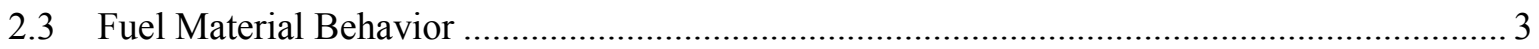

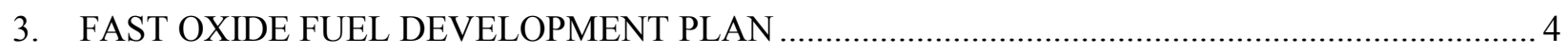

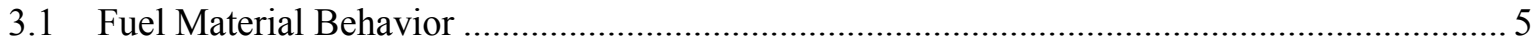

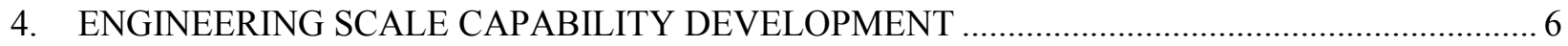

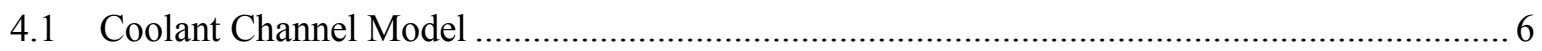

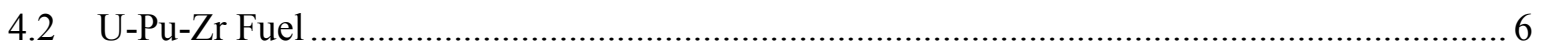

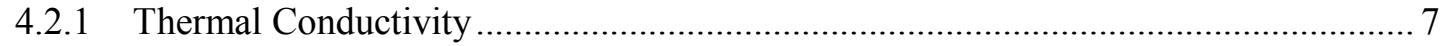

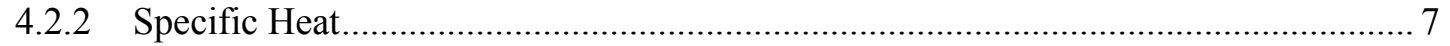

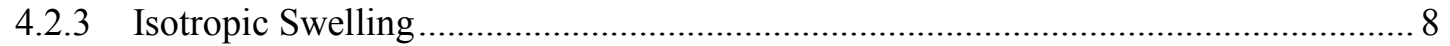

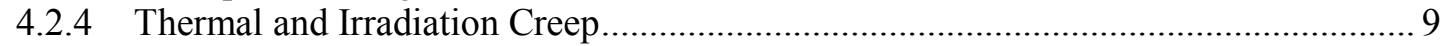

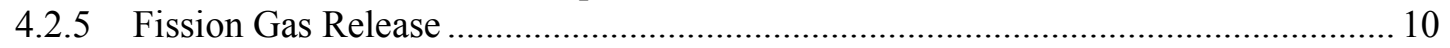

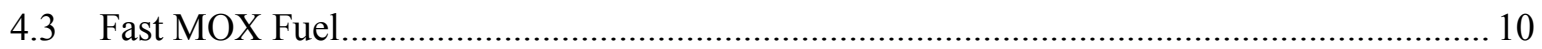

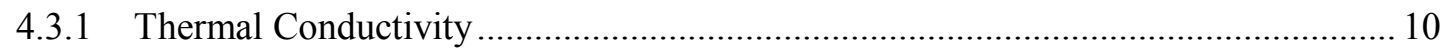

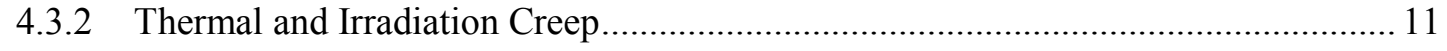

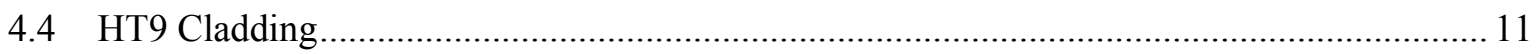

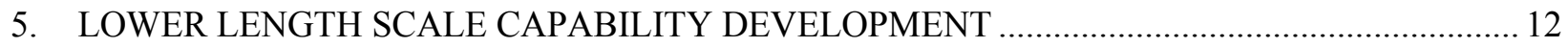

5.1 Multiphase phase field model for U-Zr binary alloys ..................................................... 12

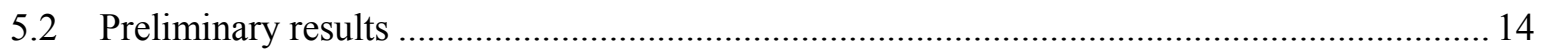

5.2.1 Phase transformation induced by a temperature gradient ........................................... 14

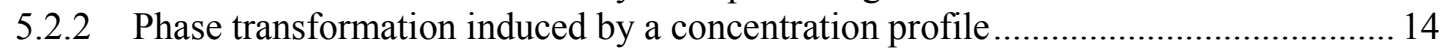

5.2.3 An attempt on the constituent redistribution in $\mathrm{UZr}$.............................................. 15

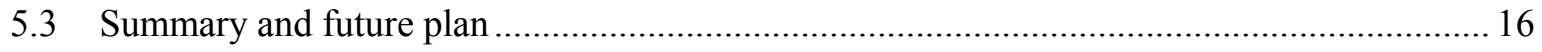

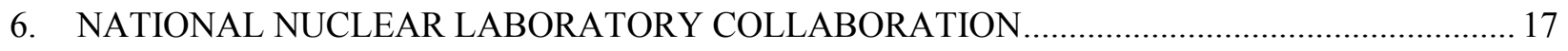

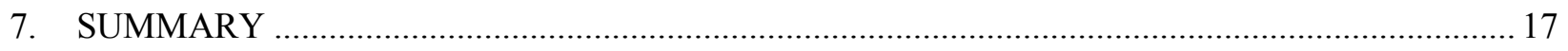

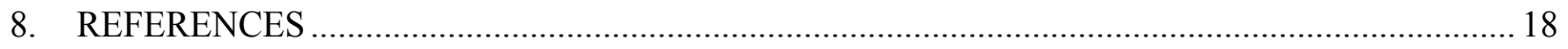




\section{FIGURES}

Fig. 1 Phase diagram of U-Zr alloy.

Fig. 2 Contours of order parameters for the $\alpha U(\eta 1=1), \beta U(\eta 2=1), \gamma U / \operatorname{Zr}(\eta 3=1)$ and the liquid phase $(\eta 4=1)$ at (a) $t=0$ and (b) $t=24,000$. In (c) the temperature and order parameter profiles at $\mathrm{t}=24,000$ along $\mathrm{y}=0$ are plotted as functions of $\mathrm{x}$.

Fig. 3 (a) free energies of $\alpha U$ and $\gamma U$ at $650{ }^{\circ} \mathrm{C}$. The initial $\alpha U$ evolved into $\gamma \mathrm{U}$ in regions where $\mathrm{cCr}>6 \%$

Fig. 4 Profiles of (a) order parameter and (b) concentration along the $\mathrm{x}$ direction at various timesteps. In (c) and (d) the contours of order parameter and concentrations at the initial and the end $(\mathrm{t}=8,000)$ of the simulation.

\section{TABLES}

Table 2.1 Material models, status and assigned priority for HT-9 cladding ........................................... 2

Table 2.2 Material models, status and assigned priority for 316SS cladding .......................................... 3

Table 2.3 Material models, status and assigned priority for D9 cladding............................................... 3

Table 2.4 Material models, status and assigned priority for $\mathrm{U}-\mathrm{Pu}-\mathrm{Zr}$ fuel............................................... 4 


\section{ACRONYMS}

TRISO Tri-structural Isotropic

MOX Mixed-oxide

LANL Los Alamos National Laboratory

FCCI Fuel Cladding Chemical Interaction

NNL National Nuclear Laboratory 
INTENTIONALLY BLANK 


\section{BISON and MARMOT Development for Modeling Fast Reactor Fuel Performance \\ 1. INTRODUCTION}

The BISON fuel performance code is a multidimensional multiphysics simulation tool being developed for the analysis of multiple nuclear fuel types under both normal operating and transient reactor conditions. In the past the bulk of development has been for light water reactor fuel, TRISO fuel particles and plate fuel [1]. There is interest in developing capabilities to mode fast reactor fuel behavior including metal and fast oxide fuels. The metal fuels of interest are uranium-plutonium-zirconium (U-Pu-Zr) alloys with three cladding options: HT9, 316SS, and the modified 316SS D9. For fast reactor oxide fuel the preferred material is high plutonium content mixed-oxide (MOX) fuel with the same three cladding options.

The MARMOT [2] code is a phase-field based code for microstructure level fuel behaviors in and out of a reactor. The in-reactor fuel behaviors are determined by their properties, which are in turn determined by their microstructure. Under operation condition, fuels are subject to concurrent high temperature and temperature gradient and neutron irradiation. Consequently, the microstructures of fuels evolve, so do their properties. In metal fuels, a high thermal gradient from the center to the rim induces phase evolution and constituent redistribution. At the same time, neutron irradiation produces lattice defects and fission products, which may further evolve into finite size defects including voids, dislocation loops, gas bubbles and precipitations. To fully capture these microstructure features is critical to assess the property degradation in these fuels. At the low length scale, in FY15 an effort has been paid to develop a phase field model for U-Zr alloys in the MARMOT code. Some preliminary results show that this model is capable of modeling the dynamic phase evolution and constituent redistribution under various conditions.

The purpose of this report is to summarize the development plans for fast reactor fuel applications including prioritization of importance and highlighting the developments incorporated into the BISON and MARMOT codes based upon those plans.

\section{METAL FUEL DEVELOPMENT PLAN}

Prior to FY15 a variety of material models applicable to metallic fuel had been developed within BISON and used in preliminary studies. The models existed in a variety of states ranging from complete (i.e., checked into the code repository with verification tests and documentation) to partially complete (e.g., checked in to the code repository but without testing or documentation) to nonexistent.

The purpose of this development plan, drafted in December 2014, is to provide a list of required material and behavioral models to analyze metallic fuel, including a current snapshot of the status of these models within BISON. This is intended to provide a clear starting point for future development efforts. Additionally, an initial prioritization of the development work going forward is proposed. This development plan is organized in three sections corresponding to 1) overall fuel element phenomena, 2) clad models and 3) fuel models.

Background information to establish the list of required models was taken principally from [3]. 


\subsection{Overall Fuel Element}

The main requirement for the overall fuel element is a convective thermal boundary condition between the fuel clad and sodium coolant that is applicable to a hexagonal rod configuration. A simple single channel coolant model is already available in BISON but includes only correlations for water assuming a square coolant channel. The plan is to provide an additional sodium option to the existing model by including an appropriate heat transfer correlation. Additionally, an option will be included to support triangular subchannel geometries. The task will include appropriate regression testing and documentation in both the user and theory manuals. This effort is identified as high priority.

\subsection{Cladding Material Behavior}

Three clad materials: 1) HT-9 commercial alloy, 2) 316 stainless steel (316SS) and 3) D9, a modified 316 stainless steel, have been identified as important for modeling fast fuel. HT-9 is a modern clad material and has the highest priority for development efforts. 31SS and D9 were more commonly used in older fuel elements and will be required primarily for code validation efforts.

Table 2.1 lists the models, December 2014 status, and assigned priorities for HT-9 material model development. Models for temperature dependent thermal conductivity and specific heat and thermal and irradiation creep model are nearly complete, only requiring further documentation in the user manual. Elasticity properties and the thermal expansion coefficient can be input as constant values or given temperature dependence using the general function capability in BISON; no dedicated material models are available. Models for clad failure and fuel clad chemical interaction (FCCI) do not exist and are assigned high and medium priority, respectively.

Tables 2.2 and 2.3 provide similar information for alloys 316SS and D9. Both are assigned low priority at this time.

Table 2.1 Material models, status and assigned priority for HT-9 cladding

\begin{tabular}{|c|c|c|c|c|c|c|}
\hline Model & Source for model & $\begin{array}{l}\text { Source code } \\
\text { name }\end{array}$ & $\begin{array}{l}\text { Regression } \\
\text { test name }\end{array}$ & $\begin{array}{l}\text { Check } \\
\text { in? }\end{array}$ & Document? & Priority \\
\hline Density & Input initial value & & & & & \\
\hline $\begin{array}{l}\text { Thermal } \\
\text { Conductivity }\end{array}$ & $\begin{array}{l}\text { Correlation from } \\
\text { Leibowitz and } \\
\text { Blomquist }\end{array}$ & ThermalHT9 & thermalHT9 & Yes & $\begin{array}{l}\text { Theory -Y } \\
\text { User - N }\end{array}$ & High \\
\hline Specific Heat & $\begin{array}{l}\text { Correlation from } \\
\text { Sharafat et al. }\end{array}$ & ThermalHT9 & thermalHT9 & Yes & $\begin{array}{l}\text { Theory - Y } \\
\text { User - N }\end{array}$ & High \\
\hline $\begin{array}{l}\text { Elastic } \\
\text { Modulus }\end{array}$ & $\begin{array}{l}\text { Input constant value } \\
\text { or function }\end{array}$ & & & & & \\
\hline Poisson Ratio & $\begin{array}{l}\text { Input constant value } \\
\text { or function }\end{array}$ & & & & & \\
\hline $\begin{array}{l}\text { Thermal } \\
\text { Expansion }\end{array}$ & $\begin{array}{l}\text { Input constant value } \\
\text { or function }\end{array}$ & & & & & \\
\hline $\begin{array}{l}\text { Thermal and } \\
\text { Irradiation } \\
\text { Creep }\end{array}$ & $\begin{array}{l}\text { Metallic Fuels } \\
\text { Handbook }\end{array}$ & $\begin{array}{l}\text { Thermal } \\
\text { Irradiation } \\
\text { CreepHT9 } \\
\end{array}$ & Creep_HT9 & Yes & $\begin{array}{l}\text { Theory - Y } \\
\text { User - N }\end{array}$ & High \\
\hline Failure Model & TBD & None & None & & & High \\
\hline FCCI & TBD & None & None & & & Medium \\
\hline
\end{tabular}


Table 2.2 Material models, status and assigned priority for 316SS cladding

\begin{tabular}{|c|c|c|c|c|c|c|}
\hline Model & Source for model & $\begin{array}{l}\text { Source code } \\
\text { name }\end{array}$ & $\begin{array}{l}\text { Regression } \\
\text { test name }\end{array}$ & $\begin{array}{l}\text { Check } \\
\text { in? }\end{array}$ & Document? & Priority \\
\hline Density & Input initial value & & & & & \\
\hline $\begin{array}{l}\text { Thermal } \\
\text { Conductivity }\end{array}$ & $\begin{array}{l}\text { Correlation from } \\
\text { Mills }\end{array}$ & Thermal316 & No & Yes & $\begin{array}{l}\text { Theory - Y } \\
\text { User - N }\end{array}$ & Low \\
\hline Specific Heat & $\begin{array}{l}\text { Correlation from } \\
\text { Mills }\end{array}$ & Thermal316 & No & Yes & $\begin{array}{l}\text { Theory - Y } \\
\text { User - N }\end{array}$ & Low \\
\hline $\begin{array}{l}\text { Elastic } \\
\text { Modulus }\end{array}$ & $\begin{array}{l}\text { Temp dependent } \\
\text { correlation }\end{array}$ & MechSS316 & No & Yes & $\begin{array}{l}\text { Theory - Y } \\
\text { User - N }\end{array}$ & Low \\
\hline Poisson Ratio & Input constant value & MechSS316 & No & Yes & $\begin{array}{l}\text { Theory }-\mathrm{Y} \\
\text { User - N }\end{array}$ & Low \\
\hline $\begin{array}{l}\text { Thermal } \\
\text { Expansion }\end{array}$ & $\begin{array}{l}\text { Temp dependent } \\
\text { correlation }\end{array}$ & MechSS316 & No & Yes & $\begin{array}{l}\text { Theory - Y } \\
\text { User - N }\end{array}$ & Low \\
\hline $\begin{array}{l}\text { Thermal and } \\
\text { Irradiation } \\
\text { Creep }\end{array}$ & TBD & None & No & No & No & Low \\
\hline Failure Model & TBD & None & No & No & No & Low \\
\hline FCCI & TBD & None & No & No & No & Low \\
\hline
\end{tabular}

Table 2.3 Material models, status and assigned priority for D9 cladding

\begin{tabular}{|c|c|c|c|c|c|c|}
\hline Model & Source for model & $\begin{array}{l}\text { Source code } \\
\text { name }\end{array}$ & $\begin{array}{l}\text { Regression } \\
\text { test name }\end{array}$ & $\begin{array}{l}\text { Check } \\
\text { in? }\end{array}$ & Document? & Priority \\
\hline Density & Input initial value & & & & & Low \\
\hline $\begin{array}{l}\text { Thermal } \\
\text { Conductivity }\end{array}$ & $\begin{array}{l}\text { Correl. from } \\
\text { MATPRO }\end{array}$ & ThermalD9 & thermalD9 & Yes & No & Low \\
\hline Specific Heat & $\begin{array}{l}\text { Correl. from } \\
\text { MATPRO }\end{array}$ & ThermalD9 & thermalD9 & Yes & No & Low \\
\hline $\begin{array}{l}\text { Elastic } \\
\text { Modulus }\end{array}$ & $\begin{array}{l}\text { Input constant value } \\
\text { or function }\end{array}$ & & & & & Low \\
\hline Poisson Ratio & $\begin{array}{l}\text { Input constant value } \\
\text { or function }\end{array}$ & & & & & Low \\
\hline $\begin{array}{l}\text { Thermal } \\
\text { Expansion }\end{array}$ & $\begin{array}{l}\text { Input constant value } \\
\text { or function }\end{array}$ & & & & & Low \\
\hline $\begin{array}{l}\text { Thermal and } \\
\text { Irradiation } \\
\text { Creep }\end{array}$ & TBD & & & & & Low \\
\hline Failure Model & TBD & & & & & Low \\
\hline FCCI & TBD & & & & & Low \\
\hline
\end{tabular}

\subsection{Fuel Material Behavior}

The highest priority and only metallic fuel material considered here is U-Pu-Zr. Table 4 lists the models, December 2014 status, and assigned priorities for model development. The main take away from Table 4 is that several models have been developed and used in preliminary studies, but have not been checked into the code repository and do not include either regression tests or documentation. The exception is a 
constituent redistribution model that was developed at LANL and documented in a journal paper [4], but has not been thoroughly tested or documented in the BISON user or theory manuals. Note that the source for existing thermal and mechanical models is known but is not included here for brevity; it will be included in the BISON theory document. With regards to fuel swelling, the existing simple isotropic model is assigned highest priority. Anisotropic swelling is believed to be significant but assigned a medium level priority at this time.

Table 2.4 Material models, status and assigned priority for $\mathrm{U}-\mathrm{Pu}-\mathrm{Zr}$ fuel

\begin{tabular}{|c|c|c|c|c|c|c|}
\hline Model & Source for model & $\begin{array}{l}\text { Source code } \\
\text { name }\end{array}$ & $\begin{array}{l}\text { Regression } \\
\text { test name }\end{array}$ & $\begin{array}{l}\text { Check } \\
\text { in? }\end{array}$ & Document? & Priority \\
\hline Density & Input initial value & & & & & \\
\hline Porosity & See theory manual & $\begin{array}{l}\text { Porosity } \\
\text { MetalAux }\end{array}$ & No & No & No & High \\
\hline $\begin{array}{l}\text { Thermal } \\
\text { Conductivity }\end{array}$ & See theory manual & $\begin{array}{l}\text { Thermal } \\
\text { UPuZr }\end{array}$ & No & No & No & High \\
\hline Specific Heat & See theory manual & $\begin{array}{l}\text { Thermal } \\
\text { UPuZr }\end{array}$ & No & No & No & High \\
\hline $\begin{array}{l}\text { Elastic } \\
\text { Modulus }\end{array}$ & $\begin{array}{l}\text { Input constant value } \\
\text { or function }\end{array}$ & & & & & \\
\hline Poisson Ratio & $\begin{array}{l}\text { Input constant value } \\
\text { or function }\end{array}$ & & & & & \\
\hline $\begin{array}{l}\text { Thermal } \\
\text { Expansion }\end{array}$ & $\begin{array}{l}\text { Input constant value } \\
\text { or function }\end{array}$ & & & & & \\
\hline $\begin{array}{l}\text { Isotropic } \\
\text { Swelling }\end{array}$ & See theory manual & $\begin{array}{l}\text { VSwelling } \\
\text { UPuZr }\end{array}$ & No & No & No & High \\
\hline $\begin{array}{l}\text { Anisotropic } \\
\text { Swelling }\end{array}$ & TBD & & & & & Med \\
\hline $\begin{array}{l}\text { Thermal and } \\
\text { Irradiation } \\
\text { Creep }\end{array}$ & See theory manual & CreepUPuZr & No & No & No & High \\
\hline $\begin{array}{l}\text { Fission Gas } \\
\text { Release }\end{array}$ & See theory manual & FgrUPuZr & No & No & No & High \\
\hline $\begin{array}{l}\text { Constituent } \\
\text { Redistribution }\end{array}$ & $\begin{array}{l}\text { LANL Report/Paper } \\
\text { [YYY] }\end{array}$ & $\begin{array}{l}\text { Constituent } \\
\text { Diffusion }\end{array}$ & $\begin{array}{l}\text { zirconium_- } \\
\text { diffusion }\end{array}$ & Yes & No & High \\
\hline
\end{tabular}

\section{FAST OXIDE FUEL DEVELOPMENT PLAN}

The purpose of this chapter is to provide a list of required material and behavioral models to analyze mixed oxide (MOX) fuel. This is intended to provide a clear starting point for future development efforts. Additionally, an initial prioritization of the development work going forward is proposed.

Since oxide and metal fuels share the same coolant and clad behavioral and material models, Sections 2.1 and 2.2 from the metal fuel development plan are applicable, and will not be repeated here. 


\subsection{Fuel Material Behavior}

To simulate MOX fuel, several material and behavioral models must be implemented or developed. The following list shows the models planned for implementation in BISON:

- Porosity as a field variable

- Central void formation

- Joint oxide gain

- Oxygen to metal ratio calculation

- Diffusion

$\begin{array}{ll}\circ & \text { Oxygen } \\ \circ & \text { Plutonium } \\ \circ & \text { Cesium }\end{array}$

- Actinide and porosity (central void formation) radial power redistribution

- Fission gas release

Other important material models for mechanics and thermal properties can be added or developed later. Background information to establish the list of required models was taken principally from [3].

The most important feature of MOX fuel behavior is accurately representing porosity migration. The first priority is to review literature and decide the best approach. Void migration occurs due to fuel boiling on the hot side of a pore, then condensing on the cool side. Pores are uniformly distributed initially, but migrate to the center of the fuel as the temperature increases forming a large hole at the fuel center.

The next priority is to create a BISON AuxKernel (or equivalent) that accounts for porosity distribution as a field variable. This model will calculate the pore migration velocity and use this as input to solve for the pore concentration. The second task is to run a preliminary simulation to verify that the porosity migrates toward the center of the fuel as expected. At that point, the team should meet and make a decision about how to handle the elements with porosity of 1 (the hole) and for how to handle the restructured zone. One possibility is to modify the elements in the "hole" to have a thermal conductivity of zero and very low stiffness, and modify the elements inside the restructured zone to have appropriate thermal and mechanical properties. Another idea regarding treatment of the hole is to modify the mesh such that the finite element domain changes from a solid circular cylinder to an annular shape.

The next priority is to account for the radial power redistribution due to the formation of the central void and corresponding diffusion of the oxygen, plutonium, and cesium.

The last priority is to add a fission gas release model, perhaps similar to the model found in [3] or equivalent.

It is worth noting that the INL is currently collaborating with the National Nuclear Laboratory (NNL) from the UK to develop MOX capability in BISON. The work scope for this collaboration is in the planning stages.

For an assessment of model development progress, preliminary calculations can be compared (where applicable) with the data set called B8-HAM, which was supplied by JAEA via our interaction with the OECD/NEA Expert Group on Innovative Fuels. 


\section{ENGINEERING SCALE CAPABILITY DEVELOPMENT}

Development at the engineering scale capability occurred in four main areas of interest: the coolant channel model, U-Pu-Zr fuel, fast MOX fuel, and HT9 cladding. The following subsections highlight the developments in each section according to the development plans described previously.

\subsection{Coolant Channel Model}

BISON contains a simple single channel coolant channel model for modeling the convective thermal boundary condition between the coolant and outside surface of the cladding. Historically this model only contained correlations for water. In fast reactor applications the coolant is liquid sodium. Therefore, an additional correlation has been added to BISON's coolant channel model to simulate a liquid sodium convective boundary condition. The model uses the modified Schad correlation:

$N u=4.496\left(-16.15+24.96\left(\frac{P}{D}\right)-8.55\left(\frac{P}{D}\right)^{2}\right) \frac{P e^{0.3}}{150}$

where

$N u \equiv h D / k$ is the Nusselt number

$P \boldsymbol{e} \equiv \operatorname{RePr}$ is the Peclet number.

$P / D$ is the pitch-to-diameter ratio

The liquid sodium material properties were taken from the ANL/RE-95/2 report [5]:

$$
\begin{aligned}
& k=124.67-0.11381 T+5.5225 \times 10^{-5} T^{2}-1.1842 \times 10^{-8} T^{3} \\
& H=-365770+1658.2 T-0.42395 T^{2}+1.4847 \times 10^{-4} T^{3}+2992600 / T
\end{aligned}
$$

where $k$ is the thermal conductivity in $\mathrm{W} / \mathrm{m}-\mathrm{K}$ and $H$ is the enthalpy in $\mathrm{J} / \mathrm{kg}$. The liquid sodium coolant channel model has been incorporated into the BISON theory and user manuals. Regression tests confirming proper operation have been added into the repository test suite.

The coolant channel model was also updated to include triangular subchannel geometry. Either a square or triangular pin array options are available, with the default being triangular if the coolant is sodium.

\subsection{U-Pu-Zr Fuel}

According to the development plan presented for metallic U-Pu-Zr fuel a variety of models had been developed and used in preliminary studies but not committed or documented in the BISON repository. Many of these models were in various stages of completeness and a significant development effort was put into ensuring coupling between different material models was done correctly. Models were developed, checked into the repository, tested and documented for thermal conductivity, specific heat, isotropic swelling, thermal and irradiation creep, and fission gas released. Mechanical properties elastic modulus, Poisson ratio and thermal expansion remain as user-defined parameters. The user can specify a constant value or function. The user must also supply a constant value for initial density. The source 
code PorosityMetalAux, listed in Table 2.4, was removed in favor of calculating the porosity in the swelling model as all porosity in U-Pu-Zr fuel comes from the gaseous swelling. This allows easier coupling between different material models that require porosity because porosity is now calculated as a material property in the simulations for which swelling is included. It is noted that the constituent redistribution model developed at Los Alamos National Laboratory (LANL) has not yet been documented in the BISON theory or user manuals.

\subsubsection{Thermal Conductivity}

A generic model for thermal conductivity for pure $\mathrm{U}, \mathrm{U}-\mathrm{Zr}$ and $\mathrm{U}-\mathrm{Pu}-\mathrm{Zr}$ alloys is given by Billone et al. [6]. The thermal conductivity of unirradiated fuel in units of $\mathrm{W} / \mathrm{m}-\mathrm{K}$ is given by

$$
k_{o}=A+B T+C T^{2}
$$

where $T$ is the temperature in Kelvin and $A, B$, and $C$ are temperature coefficients. These coefficients are given by

$$
\begin{aligned}
& A=17.5 \cdot\left(\frac{1-2.23 W_{z}}{1+1.61 W_{z}}-2.62 W_{p}\right) \\
& B=1.54 \times 10^{-2} \cdot\left(\frac{1+0.061 W_{z}}{1+1.61 W_{z}}+0.90 W_{p}\right) \\
& C=9.38 \times 10^{-6} \cdot\left(1-2.70 W_{p}\right)
\end{aligned}
$$

where $W_{p}$ and $W_{z}$ are the weight fractions of plutonium and zirconium respectively in the fuel mixture. When taking into account irradiation effects the thermal conductivity becomes

$$
k=f_{p} k_{o}
$$

where

$$
f_{p}=\frac{1-p}{1+\beta p}
$$

The porosity $p$ can be determined by the isotropic swelling material or via a user supplied function. The recommended method is to include isotropic swelling in the simulation and obtain the porosity as a material property. A warning message is displayed when the user includes isotropic swelling in the input file but does not couple the porosity material property to the thermal conductivity. Code, tests and documentation have been committed to the repository.

\subsubsection{Specific Heat}

The specific heat capacity of U-Pu-Zr alloys is dependent upon the phase $(\alpha+\delta, \beta+\gamma$ or $\gamma)$ as per Karahan [3] where the transition temperatures are taken from Savage [7], as $T_{1}=600{ }^{\circ} \mathrm{C}$ and $T_{2}=650{ }^{\circ} \mathrm{C}$.

For the $\alpha+\delta$ phase:

$$
c_{p}=26.58+\frac{0.027}{M_{A}} T
$$


For the $\gamma$ phase:

$$
c_{p}=15.84+\frac{0.026}{M_{A}} T
$$

For the $\beta+\gamma$ transition phase:

$$
c_{p}=\frac{c_{p 2}-c_{p 1}}{T_{2}-T_{1}}\left(T-T_{1}\right)+c_{p 1}
$$

where

$$
c_{p 1}=26.58+\frac{0.027}{M_{A}} T_{1}
$$

and

$$
c_{p 2}=15.84+\frac{0.026}{M_{A}} T_{2}
$$

In the above equations $T$ is the temperature in Celsius and $M_{A}$ is the average atomic mass of the fuel mixture in $\mathrm{kg}$. The specific heat model has been committed, tested and documented in the repository.

\subsubsection{Isotropic Swelling}

Isotropic swelling of U-Pu-Zr fuel is composed of two separate mechanisms: solid swelling and gaseous swelling. Swelling due to solid fission products is assumed to be $1.5 \%$ per $1 \%$ burnup as suggested by Ogata and Yokoo [8]. In terms of volumetric change in the fuel:

$$
\left(\frac{\Delta V}{V_{0}}\right)_{s}=4.16 \times 10^{-29} \mathrm{~F}
$$

where $F$ is the fission rate density in fissions $/ \mathrm{m}^{3}$. Since BISON utilizes strain increments, the average of the fission rate density from the previous and current time steps is required to obtain the correct swelling strain. The derivation of gaseous swelling was summarized in Medvedev's report [9] and is reproduced here to highlight some changes in implementation of the model prior to it being committed to the repository. First assume that the fission gas generated in the fuel instantly forms fission gas bubbles having a diameter of $5 \mu \mathrm{m}$. The mechanical force balance on an equilibrium bubble can be expressed as follows [10]:

$$
p=\frac{2 \gamma}{r_{b}}-\sigma_{h}+\sigma_{c r}
$$

where $p$ is the pressure of the fission gas in a bubble, $\gamma$ is the surface tension of the fuel, $r_{b}$ is the fission gas bubble size, $\sigma_{h}$ is the hydrostatic stress, and $\sigma_{c r}$ is the creep strength of the fuel. The gas pressure in the bubble is governed by the ideal gas law:

$$
p V=n R T
$$

where $p, V, n, R$, and $T$, are the pressure volume, amount, universal gas constant, and temperature of the fission gas, respectively. Rearranging the ideal gas law to calculate volume of the fission gas, and substituting the mechanical force balance equation obtains the following obtained for the volume of the fission gas: 


$$
V=\frac{n R T}{\frac{2 \gamma}{r_{b}}-\sigma_{h}+\sigma_{c r}}
$$

The amount of fission gas generated per unit volume of fuel is:

$n=\frac{0.26 F}{N_{A}}$

where $F$ is the fission density, 0.26 is the fission yield of gas atoms, and $N_{A}$ is Avogadro's number.

Substituting $r_{b}=0.5 \mu \mathrm{m}, \gamma=0.8 \mathrm{~N} / \mathrm{m}$ [3], and $\sigma_{c r}=6.9 \times 10^{6} \mathrm{~Pa}$ [11], the gaseous swelling of the fuel is obtained:

$$
\left(\frac{\Delta V}{V_{0}}\right)_{g}=\frac{3.59 \times 10^{-24} F T}{1.01 \times 10^{7}-\sigma_{h}}
$$

where $T$ is in Kelvin, $F$ is in fissions $/ \mathrm{m}^{3}$, and $\sigma_{h}$ is in Pa. The porosity of the fuel is calculated from the gaseous swelling via:

$$
p=\frac{\left(\frac{\Delta V}{V_{0}}\right)_{g}}{\left(\frac{\Delta V}{V_{0}}\right)_{g}+1}
$$

As with solid swelling the fission density must be taken as an average of the previous and current time steps or the gaseous swelling strain obtained will be incorrect. Previously, a BISON AuxKernel called PorosityMetalAux was developed that calculated the gaseous swelling and subsequently the porosity via Equation 21. Then in the swelling model the gaseous swelling would be determined by rearranging Equation 21 to for the gaseous swelling strain. This is nit an ideal implementation and prior to committing the swelling code to the BISON a revamping of the model occurred. In the current state PorosityMetalAux has been removed and the swelling and porosity is calculated in the swelling material model. The porosity is now a material property such that other material models like thermal conductivity and creep can be coupled. In addition, gaseous swelling is now correctly calculated in a material property rather than an AuxKernel. The fuel swelling model has been committed, tested and documented in the code repository.

\subsubsection{Thermal and Irradiation Creep}

A combined model for secondary thermal creep and irradiation creep for $\mathrm{U}-\mathrm{Pu}-\mathrm{Zr}$ fast reactor fuel has been incorporated into BISON. The constitutive relation is taken from Kutty et al. [12]:

$$
\dot{\varepsilon}=A_{1}\left(1+7.9 p+470 p^{2}\right) \sigma \cdot \exp \left(-\frac{Q_{1}}{R T}\right)+A_{2}\left(1-p^{0.67}\right)^{-0.8} \sigma^{4.5} \cdot \exp \left(-\frac{Q_{2}}{R T}\right)+A_{3} \sigma \dot{F}
$$

where $\dot{\varepsilon}$ is the creep rate (1/s), $\sigma$ is the effective (Mises) stress $(\mathrm{Pa}), T$ is the temperature $(\mathrm{K}), p$ is the porosity, $\dot{F}$ is the volumetric fission rate (fissions $\left./ \mathrm{m}^{3}-\mathrm{s}\right), Q_{i}$ are the activation energies $(\mathrm{cal} / \mathrm{mol}), R$ is the universal gas constant $(1.987 \mathrm{cal} / \mathrm{mol}-\mathrm{K})$ and $A_{1-3}$ are material constants given as $A_{1}=5 \times 10^{-3}, A_{2}=6 \times 10^{-27}$, and $A_{3}=770 \times 10^{-37}$. The first term represents diffusional thermal creep and is applicable to low stress and low temperature conditions. The second term represents thermal dislocation or power-law creep and is 
applicable to high stress and high temperature conditions. The third term represents the irradiation creep as it depends upon the fission rate. The activation energies for the thermal creep terms $\left(Q_{1}\right.$ and $\left.Q_{2}\right)$ are give as $Q_{1}=Q_{2}=52000 \mathrm{cal} / \mathrm{mol}$. The thermal and irradiation creep model has been committed, tested and documented in the code repository.

\subsubsection{Fission Gas Release}

A simplistic fission gas release model is incorporated into BISON for $\mathrm{U}-\mathrm{Pu}-\mathrm{Zr}$ fuels. According to Barnes [8] when swelling due to fission gas bubbles reaches 33\% (as calculated by Equation 20), the fission gas bubbles interconnect, and $80 \%$ of the fission gas is released. Interconnection of the fission gas bubbles transforms closed porosity into the open porosity that facilitates instant release of any consequently generated fission gas. Thus, the fission gas induced swelling is terminated once the interconnection threshold is reached. In the code, porosity is calculated with Equation 21, which is monitored in the Fission Gas Release model (read-in as a material property from the swelling model). When the porosity equals 0.24812 (corresponding to a gaseous swelling of $33 \%$ ), $80 \%$ of the fission gas is released after which, all of the fission gas that is subsequently generated is immediately released. The fission gas release model has been committed, tested and documented in the code repository.

\subsection{Fast MOX Fuel}

For fast reactor MOX fuel two material models have been developed, tested and committed to the repository: thermal conductivity, and thermal and irradiation creep. These two models were not initially listed in the development plan. In the summer an intern worked on the porosity migration mode. This model is still in the early stages and has not yet been committed or documented.

\subsubsection{Thermal Conductivity}

There are two types of MOX fuels, those used in light water reactors (LWRs) and those used in fast reactors. Fast reactor MOX has higher plutonium content than LWR MOX. Therefore, a thermal conductivity model that applies to MOX fuel with a high plutonium concentration was required. The model incorporated into BISON was developed by Inoue et al. [13] and used by Karahan [3]. The model applies to $25 \% \mathrm{PuO}_{2}$. The model consists of an unirradiated thermal conductivity that is multiplied by corrective factors for dissolved solid fission products $\left(F_{1}\right)$, precipitated solid fission products $\left(F_{2}\right)$, radiation damage $\left(F_{3}\right)$, and porosity $\left(F_{4}\right)$ as given by:

$k=F_{1} F_{2} F_{3} F_{4} k_{o}$

where $\mathrm{k}$ is the effective fuel thermal conductivity in $\mathrm{W} / \mathrm{m}-\mathrm{K}$ and $k_{o}$ is the fully dense unirradiated thermal conductivity. The unirradiated thermal conductivity is given by:

$k_{0}=\frac{1}{0.06059+0.2754 \sqrt{2-O / M \mid}+2.011 \times 10^{-4} T}+\frac{4.715 \times 10^{9}}{T^{2}} \exp \left(-\frac{16361}{T}\right)$

where $O / M$ is the oxygen-to-metal atomic ratio and $T$ is temperature in Kelvin. Lucuta et al. [14] suggested the correlations used for the solid and precipitated solid fission product, and radiation damage corrective factors. These correlations are: 


$$
\begin{aligned}
& F_{1}=\left(\frac{1.09}{\beta^{3.265}}+\frac{0.0643}{\sqrt{\beta}} \sqrt{T}\right) \arctan \left(\frac{1}{\frac{1.09}{\beta^{3.265}}+\frac{0.0643}{\sqrt{\beta}} \sqrt{T}}\right) \\
& F_{2}=1+\frac{0.019 \beta}{(3-0.019 \beta)} \frac{1}{1+\exp \left(-\frac{T-1200}{100}\right)} \\
& F_{3}=1-\frac{0.2}{1+\exp \left(\frac{T-900}{80}\right)}
\end{aligned}
$$

where $\beta$ is the burnup in atomic $\%$. The porosity correction factor is the modified Loeb correlation given by:

$$
F_{4}=1-\alpha P
$$

where $P$ is the fuel porosity and $\alpha$ is a porosity factor. For conservatism $\alpha$ is taken as 2.5. This thermal conductivity model for fast reactor MOX has been documented in the BISON user and theory manuals and has been verified with the inclusion of regression tests in the code repository.

\subsubsection{Thermal and Irradiation Creep}

The steady-state thermal and irradiation creep model for fast reactor MOX comes from an article by J. L. Routbort [15] and described by the following equation:

$$
\dot{\varepsilon}_{\text {th }+ \text { irrad }}=\frac{A}{G^{2}} \sigma \exp \left(-\frac{Q_{1}}{R T}\right)+B \sigma^{4.4} \exp \left(-\frac{Q_{2}}{R T}\right)+C \sigma \dot{F}
$$

where $R$ is the universal gas constant $(1.987 \mathrm{cal} / \mathrm{mol}-\mathrm{K}), T$ is the temperature in $\mathrm{K}, \sigma$ is the effective stress in $\mathrm{Pa}, \dot{F}$ is the fission rate in fissions $/ \mathrm{m}^{3}$-s, and $G$ is the grain size in $\mu \mathrm{m}$. The creep coefficients and activation energies are given as:

$$
A=3.23 \times 10^{9}
$$

$B=3.24 \times 10^{6}$

$C=1.78 \times 10^{-26}$

$Q_{1}=92500 \mathrm{cal} / \mathrm{mol}$

$Q_{2}=136800 \mathrm{cal} / \mathrm{mol}$

The model for steady-state thermal and irradiation creep for fast reactor MOX has been successfully committed, tested and documented in the code repository.

\subsection{HT9 Cladding}

The development plans for fast reactor fuel indicated that HT9 cladding is the highest priority for development efforts because it is a modern cladding proposed for use in fast reactor applications. 
According to the plan for metal fuel that was completed first, the material models for irradiation creep, thermal conductivity and specific heat was not documented in the theory manual. By the time the development plan for fast oxide fuels was completed these material models for HT9 martensitic steel were documented in the user manual.

The two models of interest for HT9 cladding based upon the development plans were a failure model and fuel cladding chemical interaction (FCCI). The developments were given high and medium priority respectively. The majority of development this fiscal year focused on developments and cleanup of the material models for the code and fostering of collaborative efforts with the National Nuclear Laboratory (NNL) in the UK. The details of the collaboration with NNL are discussed in detail in Section 6. Therefore, limited work has been completed in the area of an HT9 failure model and FCCI.

\section{LOWER LENGTH SCALE CAPABILITY DEVELOPMENT}

Under operation condition, metal fuels are subject to a high thermal gradient from the center to the rim, which induces phase evolution and constituent redistribution. At the same time, neutron irradiation produces lattice defects and fission products, which may further evolve into finite size defects including voids, dislocation loops, gas bubbles and precipitations. To fully capture these microstructure features is critical to assess the property degradation in fuels. At the low length scale, effort has been paid in FY15 to develop a phase field model for $\mathrm{U}-\mathrm{Zr}$ system. In the following, we will give a brief introduction on the phase field model being developed in the MARMOT code [2]. The capabilities of the model are demonstrated by some preliminary results.

\subsection{Multiphase phase field model for U-Zr binary alloys}

The phase field method is powerful for concurrent evolutions in microstructure (represented by phases) and chemical composition (concentrations). The phases in a phase field simulation are usually represented by non-conserved order parameters $\eta$. The chemical composition can be represented by conserved concentrations $c$. The material system evolves to minimize the total free energy $F[16]$. The evolution of the order parameter is given by the Allen-Cahn equation:

$\frac{\partial \eta_{i}}{\partial t}=-L_{i j} \frac{\delta F}{\delta \eta_{j}}$

And the evolution of concentrations by the Cahn-Hilliard equation:

$\frac{\partial c_{i}}{\partial t}=\nabla \cdot M_{i j} \nabla \frac{\delta F}{\delta c_{j}}$

Here $L_{i j}$ and $M_{i j}$ are parameters related to the interfacial and atomic mobilities, respectively. In general, equations (30) and (31) apply to material systems of multiple phases and components. The development of a multiphase phase field model centers on the free energy of the system. Without long-range interactions such as electric or magnetic fields, the free energy of the system can be expressed as:

$F=\oint_{V}\left(f\left(c_{i}, \eta_{i}, T\right)+w_{i j} \eta_{i} \eta_{j}+k_{i}^{c} \nabla^{2} c_{i}+k_{i j}^{\eta} \nabla \eta_{i} \nabla \eta_{j}\right) d V$

Here, $f\left(c_{i}, \eta_{i}, T\right)$ is the bulk local free energy density; $w_{i j}$ is the barrier for phase transformation; and the $k_{i}^{c}$ and $k_{i j}^{\eta}$ terms together represent the interfacial energy in terms of concentrations and order parameters. For alloys with multiple phases and components, the total free energy can be written as [17]:

$f=G^{r e f}+G^{i d}+G^{e x}$

Here, $G^{r e f}, G^{i d}$, and $G^{e x}$ represent the total Gibbs free energy for reference phases, the free energy of ideal solid solution, and the excess free energy due to mixing. For a system with multiple phases, we have 
$G^{r e f}=\sum_{i} \eta_{i} G_{i}^{0}$

Here $G_{i}^{0}$ is the bulk free energy of the $i^{\text {th }}$ phase, whose molar fraction in the material system is given by $\eta_{i}$ or a function of $\eta_{i}, h\left(\eta_{i}\right)$. For the latter case, $\eta_{i}$ will be replaced by $h\left(\eta_{i}\right)$ in equation (34). The ideal solution energy is given by

$G^{i d}=R T \sum_{i} c_{i} \log \left(c_{i}\right)$

Or by the below equation if the phase has multiple sublattices, like in the $\delta$-phase $\mathrm{UZr}_{2}$ :

$G^{i d}=R T \sum_{s l} N_{s l} \sum_{i} c_{i}^{s l} \log \left(c_{i}^{s l}\right)$

Here $R$ is the natural gas constant; $T$ is temperature; $N_{s l}$ is the fraction of atomic sites in the $s l$ sublattice;

$c_{i}^{s l}$ is the atomic fraction of component $i$ in the $s l$ sublattice. The excess energy $G^{e x}$ is given by:

$G^{e x}=\sum_{i} \sum_{j} c_{i} c_{j} L_{i, j}$

And

$L_{i, j}=\sum_{v} L_{v}\left(c_{i}-c_{j}\right)^{v}$

For parameterization, we use the parameters given in Chevalier et al. 2004 [18], which have been shown able to reproduce the U-Zr phase diagram successfully. We note that this is also the model used in the Calphad database. As shown in Fig. 1, the entire phase diagram for the U-Zr system contains six phases (or seven considering the miscibility gap of the $\gamma \mathrm{U} / \beta \mathrm{Zr}$ phase): $\alpha \mathrm{U}, \beta \mathrm{U}, \gamma \mathrm{U} / \beta \mathrm{Zr}$, $\alpha \mathrm{Zr}$, delta- $\mathrm{UZr}_{2}$ and liquid. Currently, free energies for all six phases have been implemented into the MARMOT code and are being tested using the multiphase phase field model, which is under development in MARMOT. The objective is to develop a phase field model that can describe all these phases and the phase transformation induced by changes in temperature and/or chemical composition. Although the thermodynamic database has been available for years, a multiphase phase field model utilizing the thermodynamic database for dynamic evolutions of microstructure and composition has not emerged yet, and it is highly desired. In the literature, a single-phase model has recently been developed for the $\gamma$-phase [19].

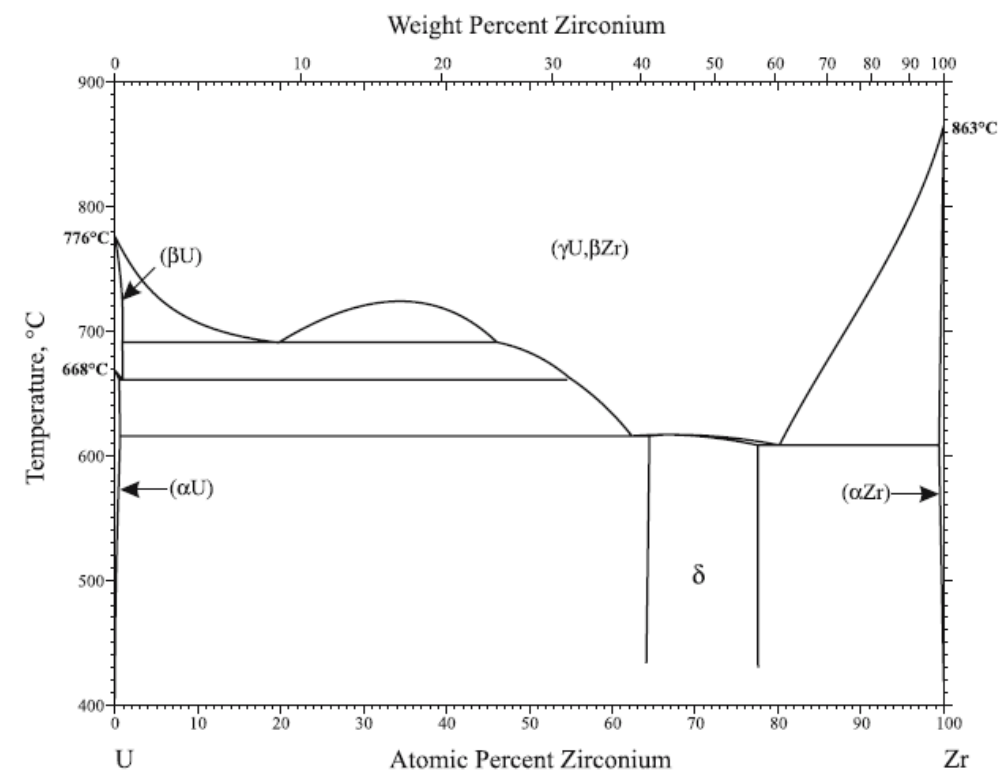

Fig. 1 Phase diagram of U-Zr alloy 


\subsection{Preliminary results}

In this section some preliminary simulation results are presented to demonstrate the crucial capabilities of the model such as the dynamic phase evolution induced by a temperature or a concentration gradient. In these simulations, the free energy models mentioned in the previous section are taken. Unless otherwise stated, constant, temperature and concentration independent mobilities are used for the concentration and order parameters. Due to the lack of data, artificial interfacial energies are used. Although physical dimensions ( $\mathrm{nm}$ for length and second for time) are used, they are meaningless until realistic mobilities and interfacial energies are used.

\subsubsection{Phase transformation induced by a temperature gradient}

For the first set of tests we focused on the phase transformation induced by a temperature gradient. In fast reactors, a temperature profile develops along the radial direction. The temperature peaks at the center and decreases monotonically towards the rim. Due to the different temperatures in different regions, multiple phases develop along the radial direction including the $\alpha \mathrm{U}, \beta \mathrm{U}$ and $\gamma \mathrm{U} / \beta \mathrm{Zr}$ phases. To test if our phase field model can capture this behavior, a multiphase phase field simulation was done on pure U. In the phase diagram, with increasing temperature four phases presents along the line of $\mathrm{cZr}=0.0$. They are all included in the simulation, and represented by four order parameters. Specifically, the $\alpha \mathrm{U}$ phase is represented by the order parameter $\eta 1, \beta \mathrm{U}$ by $\eta 2, \gamma \mathrm{U} / \mathrm{Zr}$ by $\eta 3$ and the liquid phase by $\eta 4$, respectively.

As shown in Fig. 1(a), the simulation cell is quasi-1D, with $x=1,000$ and $y=10$. Initially, all phase coexist with $\eta 1=\eta 2=\eta 3=\eta 4=0.25$ everywhere. A prescribed, static temperature profile was set up as $\mathrm{T}=573+950 * \sin (\mathrm{x} / 2000 * \pi)(\mathrm{K})$. Phases that are preferred at the corresponding temperature regions were observed to grow, and other metastable phases were found to shrink in the same region until the equilibrium state was reached. At the equilibrium state, the stable phases were found to be $\alpha \mathrm{U}(\eta 1=1)$ in the temperature region from $573 \mathrm{~K}$ to $950.3 \mathrm{~K}\left(677.3{ }^{\circ} \mathrm{C}\right), \beta \mathrm{U}(\eta 2=1)$ from $950.3 \mathrm{~K}$ to $1056.6 \mathrm{~K}(783.6$ $\left.{ }^{\circ} \mathrm{C}\right), \gamma \mathrm{U}(\eta 3=1)$ from $1056.6 \mathrm{~K}$ to $1405.0 \mathrm{~K}\left(1132.0{ }^{\circ} \mathrm{C}\right)$, and the liquid phase when $\mathrm{T}>1405.0 \mathrm{~K}$. These results are in good agreement with the Calphad database. As shown in the phase diagram in Fig.1, the $\alpha \mathrm{U}$ phase is expected to transform into $\beta \mathrm{U}$ at $668{ }^{\circ} \mathrm{C}$, and then into $\gamma \mathrm{U}$ at $776{ }^{\circ} \mathrm{C}$. Therefore, the current model is suitable for modeling the temperature induced phase transformation in $\mathrm{UZr}$ fuels.

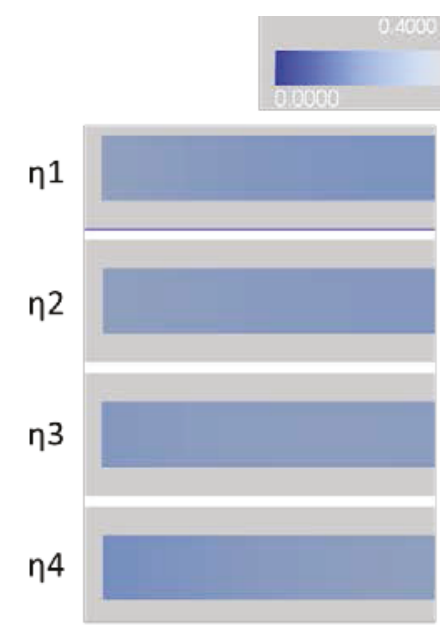

(a)

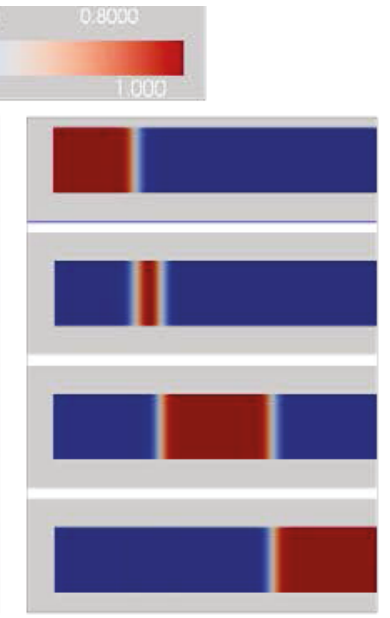

(b)

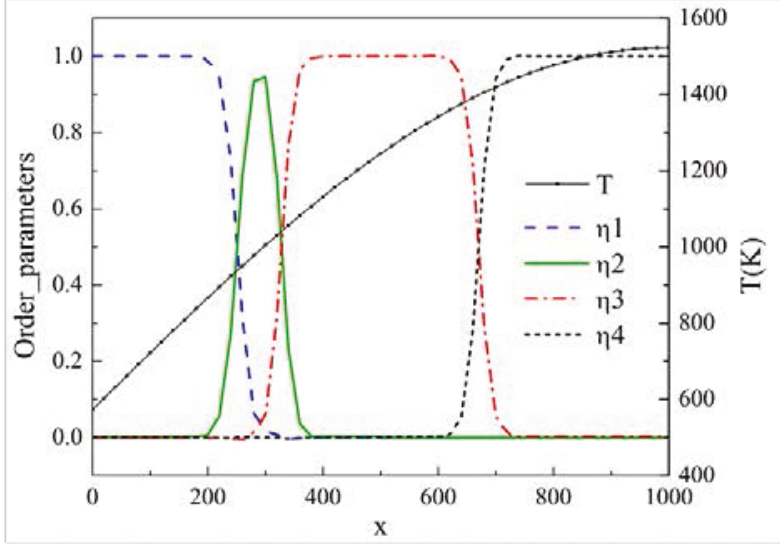

(c)

Fig. 2 Contours of order parameters for the $\alpha U(\eta 1), \beta U(\eta 2), \gamma U(\eta 3)$ and the liquid phase ( $\eta 4)$ at (a) $t=0$ and (b) $t=24,000$. In (c) the temperature and order parameter profiles at $t=24,000$ along $y=0$ are plotted as functions of the $\mathrm{x}$ coordinatePhase transformation induced by a concentration profile 


\subsubsection{Phase transformation induced by a concentration profile}

In addition to temperature, the change in local chemical composition ( $\mathrm{Zr}$ concentration) may also induce phase transformation. For instance, in a diffusion couple experiment, intermetallic phases may form due to the inter-diffusion of alloying elements. To demonstrate this capability, a phase field simulation was done at $650{ }^{\circ} \mathrm{C}$ with the $\alpha \mathrm{U}$ and $\gamma \mathrm{U} / \beta Z \mathrm{r}$ phases. Only one order parameter is used in this simulation, with the $\alpha \mathrm{U}$ phase represented by $\eta=0$ and $\gamma \mathrm{U} / \beta Z \mathrm{r}$ by $\eta=1$. The simulation started with pure $\alpha \mathrm{U}$ and a prescribed, non-evolving concentration field was set up by $\mathrm{cZr}=0.01+0.08 * \sin (\mathrm{x} / 2000 * 2 \pi)$.

At $650{ }^{\circ} \mathrm{C}$, the $\alpha \mathrm{U}$ phase is more stable than the $\gamma \mathrm{U}$ phase when cZr $<5 \%$ (Fig. 3(a)), as indicated by the lower Gibbs free energy. Due to the high local concentration at $\mathrm{x}=500$, the $\gamma \mathrm{U}$ phase was found to nucleate and grow (Fig. 3(b)) until the equilibrium state was reached. At the equilibrium state, these two phases were separated by the line of $\mathrm{cZr}=6 \%$, as shown in Fig. 3(c). (The interface between the two phases was drawn at $\eta=0.5$.) This result is in good agreement with the free energy models in the Calphad database.

(a)

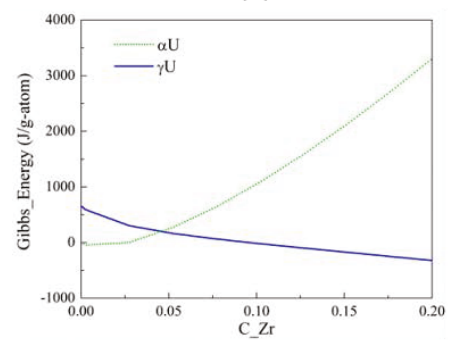

(b)

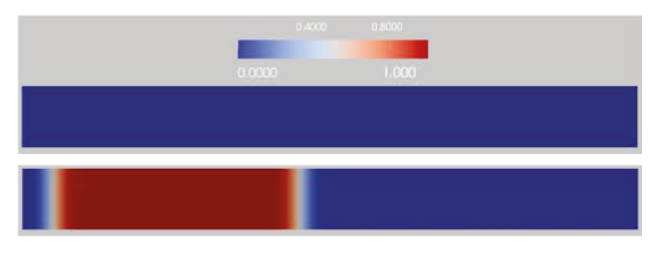

(c)

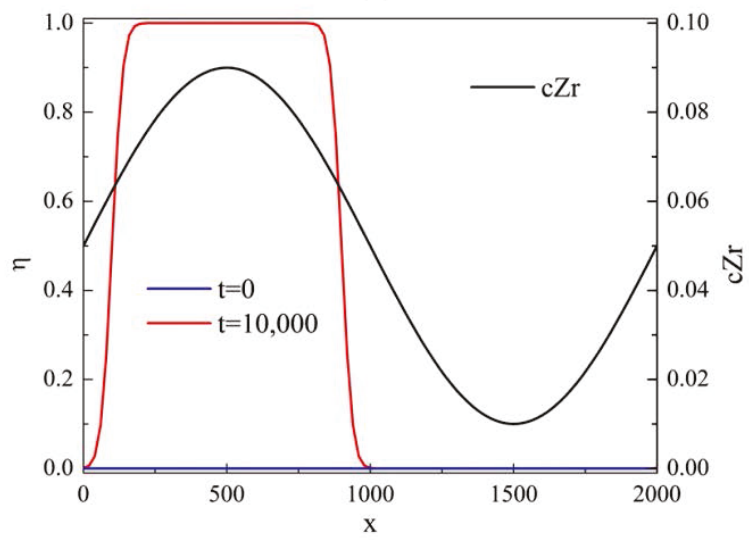

Fig. 3 (a) free energies of $\alpha \mathrm{U}$ and $\gamma \mathrm{U} / \beta \mathrm{Zr}$ at $650{ }^{\circ} \mathrm{C}$. In (b) and (c) the contour and the profile along $\mathrm{y}=0$ of the order parameter are shown at $\mathrm{t}=0$ and $\mathrm{t}=10,000$. The concentration profile is also shown in (c). As shown in (b) and (c), the initial $\alpha \mathrm{U}$ evolved into $\gamma \mathrm{U} / \beta \mathrm{Zr}$ in regions where $\mathrm{cZr}>6 \%$.

\subsubsection{An attempt on the constituent redistribution in UZr fuel}

As a further test of the current model, a simulation on the constituent redistribution was performed with the $\beta \mathrm{U}$ and $\gamma \mathrm{U} / \beta \mathrm{Zr}$ phases. To mimic the temperature gradient in a $\mathrm{UZr}$ fuel, a static temperature profile given by $\mathrm{T}=773+400 * \cos (\mathrm{x} / 100 * \pi)$ was used. A temperature dependent mobility taken from the literature [20] was used in the simulation. Initially, the simulation cell was in pure $\beta U$ phase, with a uniform concentration $\mathrm{cZr}=0.24$. After the simulation started, the $\gamma \mathrm{U} / \beta \mathrm{Zr}$ phase started to evolve in the high temperature region, and induced diffusion of $\mathrm{Zr}$ into the same region. As a result, $\mathrm{Zr}$ became depleted in the $\beta U$ phase in the intermediate region, while in the rim region it was almost intact due to the lower mobility. The concentration profile observed in the simulation is in similar shape with that from post- 
irradiation experiments in a U-Pu-Zr fuel [21]. However, in the experiments three different phases were characterized. The $\alpha \mathrm{U}$ and $\gamma \mathrm{U}$ phases were found coexist in the rim region. To fully capture the microstructure and composition distribution in the previous experiments, two dimensional multiphase simulations with all $\alpha \mathrm{U}, \beta \mathrm{U}$ and $\gamma \mathrm{U}$ phases are needed. Currently, further development is underway to have this capability fully functional. However, it is encouraging to see the right trend in the concentration profile in the preliminary results.

(a)

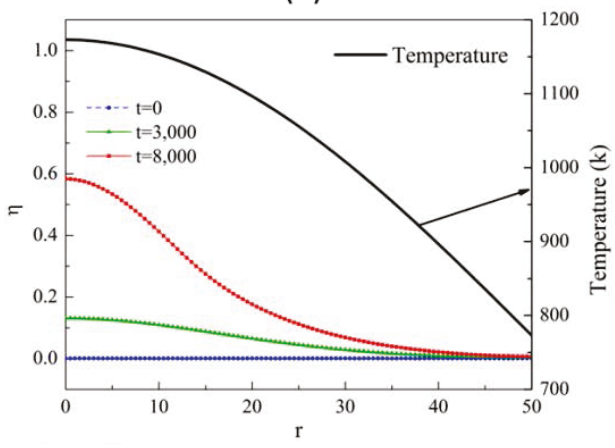

(c)

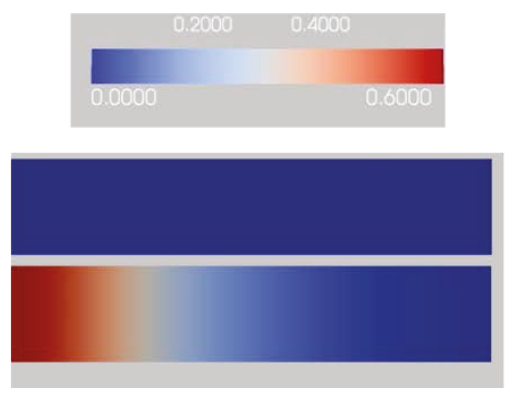

(b)

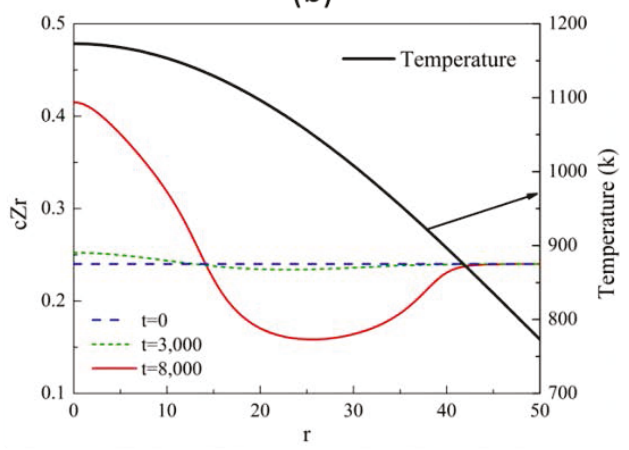

(d)

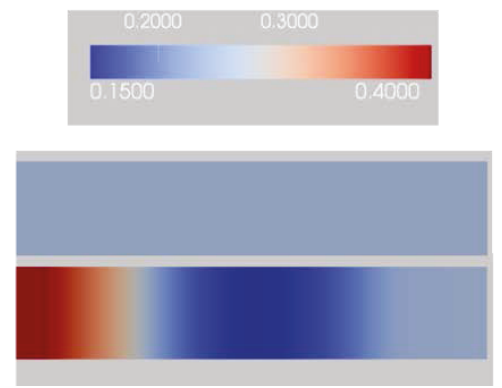

Fig. 4 Profiles of (a) order parameter and (b) concentration along the $\mathrm{x}$ direction at various timesteps. In (c) and (d) the contours of order parameter and concentrations at the initial and the end $(t=8,000)$ of the simulation.

\subsection{Summary and future plan}

At the low length scale, a multiphase phase field model has been developed. This model has been tested to be able to reproduce the $\mathrm{U}-\mathrm{Zr}$ phase diagram, and to study the phase transformation of $\mathrm{U}-\mathrm{Zr}$ alloys induced by gradients of temperature or chemical composition. After further development, this model will be capable of studying the dynamic evolutions of microstructure and chemical composition under reactor conditions.

In the future further development of the model will focus on the below areas:

1. The current model utilizes the Calphad model for each single phase. Realistic energies for material interfaces such as phase and grain boundaries are missing, and so are the mobilities for interfaces and chemical compositions. To have a predictive model that can be compared with experiments, accurate parameters for these properties are needed. They may be obtained by new experimental measurements or atomistic simulations.

2. Provided that all required material parameters are available, a multiphase phase field model is needed to model the dynamic evolutions of microstructure and composition. Currently such a model is under development and further effort is needed to make it more robust and efficient.

3. The current model is for the U-Zr binary system without considering fission products. While under operation, a large amount of fission products are produced and they affect the 
microstructure of fuels and thus their properties. In particular, gaseous fission products evolve into bubbles, leading to swelling and degradation in thermal conductivity. An effort will be paid to couple the gas bubble model in MARMOT with the U-Zr model to investigate fission gas bubble formation.

4. The current model focuses on microstructure and composition evolutions. The eventual objective is to predict the consequent changes in material properties. In the future, material models and homogenization algorithms linking the microstructure and material properties will be incorporated with the $\mathrm{U}-\mathrm{Zr}$ model, to model the transient microstructure and fuel properties.

\section{NATIONAL NUCLEAR LABORATORY COLLABORATION}

Throughout the fiscal year significant effort has been put towards generating a bilateral agreement between the INL and the NNL in the UK. It is important to note that this section highlights the thoughts and discussions within the BISON team of where each participating team can contribute. The general perspective of the collaboration involves the exchange of NNL fuel performance experience for INL computational capabilities.

The plan is to utilize this bilateral agreement to facilitate the development of the fast reactor MOX capabilities in BISON. To do this a BISON license has already been put in place with NNL, and HPC accounts and security plans have been put in place for three NNL employees. One of these employees, Brendan Perry, is scheduled to visit the INL for about one month around October 2015, to come up to speed with BISON and to prep for NNL development activities. In addition to providing access to BISON and providing training, INL would be responsible for assisting NNL with code developments and commits, as well as using the new capabilities in validation simulations.

From the perspective of NNL it is suggested that they will provide insight into the fast reactor capabilities currently available in their fuel performance code TRAFIC and propose features to be included into BISON. Upon agreement by all parties NNL would complete the majority of development of the fast reactor capability with oxide fuel.

The benefits of such collaboration extend further than just the participants in this collaborative effort. For example, all BISON users will gain the capability of modeling fast reactor fuel performance. In addition, the INL gains the benefit of having the sustainability and usefulness of BISON would increase because it becomes part of an international collaborative project. NNL is provided with a flexible and computationally advanced tool for fuel performance analyses that is not possible with their current codes. Examples include: 3D effects (e.g., chipped pellets, fuel eccentricity, azimuthal variations in cooling), multi-scale simulation, hydrogen migration in cladding, coated particle fuel and plate fuel, among others. In addition to fast reactor development INL could gain access to a large suite of non-proprietary validation cases. There is the possibility of transferring data from 233 rod irradiations $\left(210 \mathrm{UO}_{2}\right.$ rods, 9

MOX rods, 5 (U, Gd) $\mathrm{O}_{2}$ rods).

\section{SUMMARY}

In summary, development plans were created for fast reactor applications including cladding materials (316SS, D9, and HT9), fuel materials (U-Pu-Zr and MOX) and the convective boundary condition for liquid sodium coolant. Next an in-depth look into the accomplishments and developments at the engineering and lower length was presented. Finally, a brief introduction into the initial work into setting up a bilateral agreement between INL and NNL in regards to fast reactor MOX development. 


\section{REFERENCES}

1. R. L. Williamson, J. D. Hales, S. R. Novascone, M. R. Tonks, D. R. Gaston, C. J. Permann, D. Andrs and R. C. Martineau, "Multidimensional multiphysics simulation of nuclear fuel behavior," Journal of Nuclear Materials, 423:149-163, 2012.

2. M. R. Tonks, D. Gaston, P. C. Millett, D. Andrs, and P. Talbot, "An object-oriented finite element framework for multiphysics phase field simulations", Computational Materials Science 51: 20-29, 2012.

3. A. Karahan, "Modeling of thermo-mechanical and irradiation behavior of metallic and oxide fuels for sodium fast reactors," PhD thesis, Massachusetts Institute of Technology, June 2009.

4. J. Galloway, C. Unal, N. Carlson, D. Porter and S. Hayes, "Modeling Constituent Redistribution in U$\mathrm{Pu}-\mathrm{Zr}$ Metallic Fuel Using the Advanced Fuel Performance Code BISON," Nuclear Engineering and Design, 286, 1 (2015)

5. J. K. Fink and L. Leibowitz, "Thermodynamic and transport properties of sodium liquid and vapor," Technical Report ANL/Re-95/2, ANL Reactor Engineering Division, 1995.

6. M. C. Billone, Y. Y. Liu, E. E. Gruber, T. H. Hughes and J. M. Kramer, "Status of Fuel Element Modeling Codes for Metallic Fuels," In Proceedings of American Nuclear Society International Conference on Reliable Fuels for Liquid Metal Reactors, Tucson, Arizon, September 7-11, 1968.

7. H. Savage, "The heat content and specific heat of some metallic fast-reactor fuels containing plutonium," Journal of Nuclear Materials, 25:584-594, 2006.

8. T. Ogata and T. Yokoo, "Development and Validation of ALFUS: An Irradiation Behavior Analysis Code for Metallic Fast Reactor Fuels," Journal of Nuclear Technology, 128(1):113-123, 1999.

9. P. Medvedev, "Fuel performance modeling results for representative FCRD irradiation experiments: Projected deformation in the annular AFC-3A U-10Zr fuel pins and comparison to alternative designs," Technical Report INL/EXT-12-27183 Rev. 1, Idaho National Laboratory, 2012.

10. R. S. Barnes, "A Theory of Swelling and Gas Release for Reactor Materials," Journal of Nuclear Materials, 11:135-148, 1964.

11. A. T. Churchman, R. S. Barnes, and A. H. Cottrell, "Effects of Heat and Pressure on the Swelling of Irradiated Uranium," Nuclear Energy, 7:88-96, 1958.

12. T. R. G. Kutty, C. B. Basak, A. Kumar, and H. S. Kamath, "Creep behavior of $\delta$-phase of U-Zr system by impression creep technique," Journal of Nuclear Materials, 408:90-95, 2010.

13. M. Inoue, K. Maeda, K. Katsuyama, K. Tanaka, K. Mondo and M. Hisada, "Fuel-to-cladding gap evolution and its impact on thermal performance of high burnup fast reactor type uranium-plutonium oxide fuel pins," Journal of Nuclear Materials, 326(1):59-73, 2004.

14. P. G. Lucuta, H. J. Matzke and I. J. Hastings, "A pragmatic approach to modeling thermal conductivity of irradiated $\mathrm{UO}_{2}$ fuel: review and recommendations," Journal of Nuclear Materials, 232:166-180, 1996.

15. J. L. Routbort, "Compressive creep of mixed oxide fuel pellets," Journal of Nuclear Materials, 44:247-259, 1972.

16. L. Q. Chen, "Phase-field models for microstructure evolution", Annu. Rev. Mater. Res., 32: 113-40, 2002.

17. P.Y. Chevalier, E. Fischer, "Thermodynamic modelling of the O-U-Zr system", Journal of Nuclear Materials, 257: 213-255, 1998.

18. P. Y. Chevalier, E. Fischer and B. Cheynet, "Progress in the thermodynamic modelling of the O-UZr ternary system", Computer Coupling of Phase Diagrams and Thermochemistry 28: 15-40, 2004.

19. R. R. Mohanty, J. Bush, M. A. Okuniewski and Y. H. Sohn, "Thermotransport in $\gamma($ bcc) U-Zr alloys: A phase-field model study", Journal of Nuclear Materials, 414: 211-216, 2011.

20. W. Li, R.ui Hu, Y. W. Cui, H. Zhong, H. Chang, J. Li, and L. Zhou, "Computational study of atomic mobility for the bcc phase of the U-Pu-Zr ternary system", Journal of Nuclear Materials, 407: 220$227,2010$. 
21. G. L. Hofman, S. L. Hayes and M. C. Petri, “Temperature gradient driving constituent redistribution in U-Zr alloys", Journal of Nuclear Materials, 227: 277-286, 1996. 